\title{
Persepsi Pengunjung Terhadap Kualitas Pelayanan Di Nav Karaoke Pekanbaru
}

\author{
DELFI YANTI \\ Sekolah Tinggi Pariwisata Riau \\ Jln. Pattimura No. 54 Pekanbaru-Riau \\ E-mail : delfiyanti@gmail.com
}

\begin{abstract}
Based on the results of the writings and observations of the authors, the following conclusions can be drawn. Based on the results of the researchers' interviews with Pekanbaru karaoke NAV supervisors, it can be concluded, that the Pekanbaru karaoke NAV management has prepared efforts to improve service quality and regulations for customers and employees. In the demographic data of visitors who gave their perceptions of the quality of NAV karaoke services in Pekanbaru, it is known that the majority are male, aged 17-27 years old, high school education, residing in Pekanbaru and employment as students. The average visitor visits for 1-4 hours, chooses the type of medium room, likes pop songs and visits at night. Based on the results of the analysis that the author has obtained, it can be concluded that the visitor's perception of the quality of the Pekanbaru karaoke NAV service as a whole is good / positive. Among the five variables analyzed, the variable that was rated the best by NAV karaoke visitors in Pekanbaru was the tangible variable / physical evidence
\end{abstract}

Keywords: Perception, Quality Service

Salah satu tujuan utama yang ingin dicapai oleh Negara berkembang pada saat ini adalah tercapainya perekonomian yang kuat pondasinya. Industri pariwisata merupakan peran yang sangat penting di dalam perekonomian bagi negara-negara yang memiliki sumber daya manusia. Usaha pariwisata adalah kegiatan yang bertujuan menyelenggarakan jasa pariwisata, menyediakan atau mengusahakan objek dan daya tarik wisata, usaha sarana pariwisata dan lain yang terkait di bidang tersebut. Sebagaimana disebutkan, salah satu sarana penting untuk memenuhi kebutuhan orang yang berpergian lebih dari sehari.

Pada prinsipnya karaoke adalah salah satu bentuk perdagangan jasa. Setiap pengusaha karaoke berusaha untuk memberikan pelayanan yang maksimal bagi para tamunya. Yoetti (2004) mengungkapkan bahwa jasa adalah suatu produk yang tidak nyata (intangible) dan hasil kegiatan timbal balik antara pemberi jasa dan penerima jasa melalui satu atau beberapa aktivitas untuk memenuhi kebutuhan pelanggan.
Karaoke keluarga adalah tempat hiburan dimana pengunjung dapat bernyanyi bersama keluarga, temanteman, teman kerja dan relasi kerja dalam suasana kekeluargaan dan bersih serta jauh dari kesan maksiat. NAV ( Nirwana Audio Visual ) sebagai salah satu karaoke terdepan yang berkonsep keluarga, menawarkan tempat bernyanyi untuk keluarga yang bebas dari narkoba, minuman-minuman keras, dan prostitusi. Saat ini NAV ( Nirwana Audio Visual ) karaoke keluarga di kota Pekanbaru merupakan salah satu tempat hiburan yang banyak dipilih oleh sebagian masyarakat. Segudang aktifitas yang dilalui masyarakat perkotaan akhir-akhir ini memaksa mereka untuk menetralisasikan kepenatan mereka dengan berkaraoke sebagai pelampiasannya. Disadari ataupun tidak, karaoke telah mengubah gaya hidup mereka.

Perkembangannya yang pesat telah menjadikan karaoke sebagai trend lifestyle masa kini. Beragam konsep hiburan karaoke ditawarkan untuk 
menarik minat masyarakat kota besar seperti Pekanbaru. Menjamurnya pusat hiburan karaoke selanjutnya menimbulkan persaingan sangat ketat diantara perusahaan yang bergerak di bisnis serupa. Persaingan ini kemudian membuat setiap perusahaan harus meningkatkan kualitas pelayanan yang diberikan dan selalu memperhatikan perilaku konsumen mereka.

Kualitas pelayanan adalah kesesuaian dan derajat kemampuan untuk digunakan dari keseluruhan karakteristik produk dan jasa yang disediakan dalam pemenuhan harapan yang dikehendaki konsumen dengan atribut atau faktor yang meliputi : bukti langsung, perhatian pribadi dari karyawan kepada konsumen, daya tanggap, keandalan dan jaminan (Hutasoit, 2011). Definisi Kualitas pelayanan menurut Tjiptono (2011: 164) adalah upaya pemenuhan kebutuhan dan keinginan pelanggan serta ketepatan penyampaiannya untuk mengimbangi harapan pelanggan. Sehingga dapat disimpulkan kualitas pelayanan merupakan suatu pernyataan tentang sikap, hubungan yang dihasilkan dari perbandingan antara ekspektasi (harapan) dengan kinerja (hasil).

Kepuasan konsumen adalah tingkat perasaan seseorang setelah membandingkan kinerja (atau hasil) yang ia rasakan dibandingkan dengan harapannya. Kepuasan konsumen dapat diartikan sebagai hasil akumulasi dari konsumen atau konsumen dalam menggunakan produk dan jasa. Kepuasan konsumen juga dapat dideskripsikan sebagai sesuatu yang dipengaruhi oleh nilai-nilai suatu layanan yang disuguhkan oleh pegawai kepada pelanggan.

Bisnis jasa adalah aktivitas atau manfaat yang ditawarkan untuk dijual secara esensial tidak berwujud dan tidak menghasilkan kepemilikan atas apapun. Kotler \& Amstrong (2007). Selain itu Wikipedia (2008) juga mendefinisikan bahwa bisnis jasa adalah bisnis yang menghasilkan barang intangible, dan mendapatkan keuntungan dengan cara meminta bayaran atas jasa yang mereka berikan. Sedangkan Rangkuti (2006) menyebutkan jasa merupakan pemberian suatu kinerja atau tindakan tak kasat mata dari satu pihak kepada pihak lain. Pada umumnya jasa diproduksi dan dikonsumsi pada saat bersamaan, dimana interaksi antara pemberian jasa mempengaruhi hasil jasa tersebut. Dari definisi diatas maka dapat disimpulkan bisnis jasa adalah bisnis yang menghasilkan produk yang tak dapat dilihat dan diproduksi bersamaan pada saat terjadinya interaksi antara penjual dan penggunanya.

Senada dengan hal tersebut, di Kota Pekanbaru berkembang objek-objek wisata hiburan umum yang ternyata memang lebih cepat kemajuannya. Objek wisata hiburan umum yang banyak tumbuh dan berkembang salah satunya adalah Karaoke. Perkembangan industri jasa hiburan ini ternyata memberikan warna tersendiri terhadap kehidupan sosial masyarakat di kota ini, bahkan mengakibatkan terjadinya perubahan sosial budaya. Beberapa hal yang diduga menjadi pangkal sebab terjadinya perubahan-perubahan dimaksud adalah karena dalam hiburan umum itu tumbuh dan berkembang kegiatan perjudian gelap, konsumsi obat-obat terlarang, dan prostitusi terselubung.

Robbins dan Judge (2008) mendefinisikan persepsi (perception) sebagai proses di mana individu mengatur dan menginterpretasikan kesan kesan sensoris mereka guna memberikan arti bagi lingkungan mereka. Menurut Gibson et al. (1996), persepsi adalah proses seseorang untuk memahami lingkungan yang meliputi orang, obyek, simbol, dan sebagainya yang melibatkan proses kognitif. Proses kognitif merupakan proses pemberian arti yang melibatkan tafsiran pribadi terhadap rangsangan yang muncul dari obyek tertentu. Oleh karena tiap-tiap individu memberikan makna yang melibatkan tafsiran pribadinya pada obyek tertentu, maka masing-masing individu akan memiliki persepsi yang berbeda meskipun melihat objek yang 
sama. Hal yang sama juga diungkapkan oleh Robbins (2002) bahwa riset tentang persepsi secara konsisten menunjukkan bahwa individu yang berbeda dapat melihat hal yang sama tetapi memahaminya secara berbeda.

Persepsi dipengaruhi oleh berbagai faktor yang menyebabkan seseorang individu dapat memberikan interpretasi yang berbeda dengan orang lain pada saat melihat sesuatu. Menurut Jalalludin (2003) faktor-faktor yang mempengaruhi persepsi adalah : Faktor fungsional, Faktor stuktural dan Faktor kebudayaan.

Kotler (2007) menjelaskan bahwa perkembangan manajemen pemasaran ke depan lebih banyak ditandai oleh jasa, karena semakin sulit bagi pemasar untuk memisahkan produk yang dapat dengan tegas membedakan atara barang atau jasa. Terhadap pemasaran jasa sekalipun, masih ditemui barang yang ditawarkan. Akan tetapi, satu hal yang tak ditolak adalah maraknya jasa di bidang hiburan (entertain). Tujuan dari kegiatan pemasaran adalah secara umum diyakini untuk memenuhi kebutuhan pelanggan secara memuaskan.

Aswadi Rahmad pada tahun 2012 melakukan penelitian mengenai analisis persepsi konsumen terhadap pelayanan karaoke Inul Vizta Family outlet cabang kota Jambi. Hasil penelitiannya menunjukkan bahwa persepsi konsumen untuk lima indikator yaitu dimensi tangibel, dimensi realibility, dimensi responsiveness, dimensi assurance dan dimensi emphaty mempunyai nilai rata-rata positif atau baik di Inul Vizta cabang kota Jambi. Berarti dalam penelitian ini semua indikator kualitas pelayanan di nilai baik oleh konsumen terhadap pelayanan karaoke Inul Vizta family outlet cabang Kota Jambi.

Dalam penelitian Wahyu Nurlistiya (2009) meneliti analisis pengaruh variabel kualitas pelayanan terhadap kepuasan konsumen pada NAV karaoke cabang Depok. Hasil penelitiannya menunjukkan bahwa dari kelima variabel kualitas pelayanan yang telah diuji dan dianalisi dapat disimpulkan bahwa ada pengaruh nyata secara bersama kualitas pelayanan yaitu keandalan (reliability), ketanggapan (responsivenes), jaminan (assurance), empati (emphaty), dan berwujud (tangible) terhadap kepuasan konsumen pada NAV karaoke cabang Depok

\section{METODE}

Penelitian ini adalah penelitian survei (survey research) yang berupa penelitian penjelasan. Dalam survei, informasi diperoleh dengan menggunakan kuesioner yang datanya dikumpulkan dari responden atau populasi yang akan menjadi sampel penelitian. Penelitian ini mengenai persepsi pengunjung terhadap kualitas pelayanan di NAV karaoke Pekanbaru. Penelitian dilakukan pada pengunjung yang datang berkaraoke di NAV Pekanbaru.

Populasi adalah seluruh objek yang diteliti (Suharsimi Arikunto, 2010). Baik berupa orang, benda ,kejadian, nilai maupun hal yang terjadi. Sesuai dengan sasaran yang akan dicapai yaitu tentang kualitas pelayanan di NAV karaoke Pekanbaru maka yang menjadi populasi adalah pengunjung di NAV karaoke keluarga Pekanbaru.

Instrumen penelitian digunakan untuk mengukur nilai variabel yang akan diteliti. Dengan demikian jumlah instrumen yang digunakan untuk penelitian tergantung pada jumlah yang akan di teliti. Instrumen penelitian akan digunakan untuk melakukan pengukuran dengan tujuan untuk menghasilkan data kuantitatif yang akurat, maka setiap instrumen harus memiliki skala, skala dalam instrument penelitian terdiri dari beberapa jenis diantaranya skala likert, skala guttman, sistematic different dan rating scale.

\section{HASIL}

Untuk mengetahui upaya apa saja yang dilakukan supervisor dalam meningkatkan kualitas pelayanan, peneliti melakukan wawancara dengan salah seorang supervisor yang ada di NAV karaoke Pekanbaru. Adapun upaya-upaya 
yang dilakukan supervisor dalam meningkatkan kualitas pelayanan berdasarkan hasil wawancara adalah sebagai berikut : Dalam melengkapi fasilitas yang ada di tempat karaoke, supervisor mengetahui fasilitas yang masih kurang atau fasilitas yang sudah tidak layak pakai adalah dari laporan karyawan dan komplain/saran pengunjung terhadap fasilitas yang ada. Upaya yang dilakukan jika fasilitas yang dirasa sangat penting dan keadaan keuangan memungkinkan, fasilitas tersebut langsung di perbaharui atau diadakan.

Jika jumlah karyawan dirasa masih kurang dalam melayani pelanggan pada saat ramai supervisor akan menambah tenaga karyawan/ jam kerja atau terjun langsung kelapangan. Untuk meningkatkan kinerja karyawan dalam bekerja, supervisor melakukan breeffing dengan karyawan dengan memberikan bimbingan, perhatian dan motivasi kepada karyawan.

Dalam meningkatkan daya tanggap karyawan terhadap konsumen, supervisor juga menyediakan hadiah/imbalan bagi mereka yang berprestasi apabila berhasil dalam mencapai target atau pelayanan sesuai dengan target yang ditetapka, sehingga semangat dalam berprestasi dan memberikan pelayanan menjadi tinggi.

Dalam menghadapi hal-hal yang tidak diinginkan supervisor memberikan beberapa peraturan penting yang harus dipatuhi oleh karyawan dan pengunjung yang di tempelkan pada setiap ruangan di NAV karaoke Pekanbaru. Jika terdapat pengunjung yang melanggar peraturan tersebut seperti melakukan hal-hal yang tidak diizinkan di dalam ruangan maka akan di tindak lanjuti secara hukum, dan jika yang melakukan itu adalah karyawan seperti mengkonsumsi obat terlarang maka karyawan tersebut akan dipecat dan diserahkan ke polisi.

Kebutuhan para pelanggan sangat penting, karena ketidak nyamanan pelanggan pasti akan merugikan tempat karaoke. Dalam memahami kebutuhan pelanggan supervisor menunjuk salah satu koordinator lapangan dari karyawannya, yang berguna untuk mencatat semua kendala dilapangan dan komplain para pelanggan dan mengkomunikasikan kepada supervisor setiap hari, sehingga supervisor mengetahui kendala apa yang harus dibenahi cepat dan komplain apa saja yang diberikan pengunjung atas kualitas pelayanan.

Pengunjung NAV karaoke Pekanbaru lebih banyak laki-laki yaitu $57,5 \%$ daripada perrempuan $42,5 \%$. Berdasarkan pengamatan penulis dilapangan, pengunjung NAV karaoke Pekanbaru memang banyak laki-laki dari pada perempuan, karena tempat karaoke memang lebih banyak dikunjungi malam hari dibandingkan siang hari, oleh sebab itu pengunjung laki-laki yang pada umumnya lebih menyukai keluar dimalam hari lebih banyak dibandingkan perempuan. Untuk itu pada NAV karaoke lebih mendahulukan kualitas pelayanan bagi laki-laki dibandingkan denganan perempuan, karena mayoritas pengunjungnya laki-laki.

Bahwa pengunjung NAV karaoke Pekanbaru lebih banyak yang berusia 17-27 tahun $(77.5 \%)$ dibandingkan dengan usia $>27$ tahun. Pada umunya usia 17-27 tahun adalah tergolong usia remaja dan dewasa, sehingga NAV karaoke Pekanbaru lebih meningkatkan kualitas pelayanan bagi remaja yang pada umunya menyukai hal yang praktis dan suka berdandan, seperti memasang cermin di setiap ruangan.

Pengunjung NAV karaoke Pekanbaru mayoritas lulusan SMA. Ini dibuktikan dari hasil penelitian yang menunjukkan pengunjung lulusan SMA $55 \%$, SMP 15\%, D3 2,5\% dan S1 2,5\%. Jadi persepsi yang diberikan oleh pengunjung lebih akurat karena dinilai dari pendidikan mereka, semuanya berpendidikan dengan pendidikan terendah adalah SMP.

Pengunjung NAV karaoke Pekanbaru semuanya bertempat tinggal di Kota Pekanbaru (100\%). Berdasarkan pengamatan peneliti di lapangan, memang mayoritas dari pengunjung menggunakan kendaraan roda dua yang menandakan tempat tinggal mereka tidak jauh dari NAV karaoke Pekanbaru. Pengunjung dapat 
memberikan Persepsi mereka dengan sebaik mungkin atas kualitas pelayanan NAV karaoke Pekanbaru, karena pengunjung yang bertempat tinggal di Pekanbaru mampu membandingkan dengan kualitas pelayanan tempat karaoke lain atau saingan NAV karaoke Pekanbaru.

Waktu kunjung yang paling banyak dikunjungi yaitu pada malam hari sebesar $75 \%$, dalam hal ini karaoke lebih memperbanyak karyawan untuk bekerja pada malam hari, agar kualitas pelayanan di tempat karaoke tidak menurun.

\section{PEMBAHASAN}

Statistik deskriptif mengenai variabelvariabel penelitian meliputi persepsi pengunjung terhadap kualitas layanan yang terdiri dari tangible, reliability, responsiveness, assurance dan emphaty disajikan dalam tabel yang menunjukkan angka kisaran teoritis, kisaran sesungguhnya, rata-rata dan standar deviasi disajikan dalam tabel. Pada tabel tersebut disajikan kisaran teoritis yang merupakan kisaran atas bobot jawaban yang secara teoritis didesain dalam kuesioner dan kisaran sesungguhnya yaitu nilai terendah sampai nilai tertinggi atas bobot jawaban responden yang sesungguhnya.

NAV karaoke Pekanbaru harus mampu memberikan bukti langsung atau menunjukkan eksistensi kepada pihak eksternal/pengunjung seperti penampilan, kemampuan sarana, prasarana fisik dan keadaan lingkungan yang bagus. Dengan memberikan bukti langsung yang membuat konsumen nyaman, maka konsumenpun tidak ragu lagi atas pelayanan yang diberikan. Berikut tanggapan konsumen/pengunjung NAV karaoke Pekanbaru terhadap bukti langsung/ tangible yang ada pada NAV karaoke, untuk variabel tangible mempunyai bobot kisaran teoritisnya antara 10 sampai dengan 50 dengan rata-rata sebesar 30 . Pada kisaran sesungguhnya variabel tangible mempunyai bobot jawaban antara 35 sampai dengan 50 dengan rata-rata sebesar 43,15. Dapat dilihat bahwa nilai rata-rata jawaban atas variabel tangible bobot jawaban kisaran sesungguhnya berada di atas rata-rata kisaran teoritis, maka dapat disimpulkan bahwa pengaruh variabel tangible terhadap responden adalah tinggi, dan pada NAV karaoke Pekanbaru persepsi konsumen terhadap indikator tangiblel bukti fisik adalah baik atau positif.

Keandalan suatu perusahaan jasa sangat menentukan kualitas pelayanan yang di berikan kepada konsumen, jika keandalan tidak dapat dipertahankan lagi maka kecenderungan perusahaan tersebut tidak dipercayai konsumen. Berikut tanggapan konsumen terhadap indikator keandalan/ reliability di NAV karaoke Pekanbaru, untuk variabel reliability mempunyai bobot kisaran teoritisnya antara 9 sampai dengan 45 dengan rata-rata sebesar 27. Pada kisaran sesungguhnya variabel reliability mempunyai bobot jawaban antara 33 sampai dengan 45 dengan rata-rata sebesar 38,18. Dapat dilihat bahwa nilai rata-rata jawaban atas variabel reliability bobot jawaban kisaran sesungguhnya berada di atas rata-rata kisaran teoritis, maka dapat disimpulkan bahwa pengaruh variabel reliability terhadap responden adalah tinggi, dan pada NAV karaoke Pekanbaru persepsi konsumen terhadap indikator reliability/ keandalan adalah baik atau positif.

Daya tanggap yang dimiliki oleh suatu perusahaan terhadap konsumen harus tinggi, atau kritis dalam memenuhi kepuasan konsemen. Berikut tanggapan konsumen terhadap indikator daya tanggap/ responsiveness di NAV karaoke Pekanbaru, untuk variabel assurance mempunyai bobot kisaran teoritisnya antara 10 sampai dengan 50 dengan rata-rata sebesar 30. Pada kisaran sesungguhnya variabel assurance mempunyai bobot jawaban antara 32 sampai dengan 50 dengan rata-rata sebesar 41,22. Dapat dilihat bahwa nilai rata-rata jawaban atas variabel assurance bobot jawaban kisaran sesungguhnya berada di atas rata-rata kisaran teoritis, maka dapat disimpulkan bahwa pengaruh variabel assurance terhadap responden adalah tinggi, dan persepsi konsumen pada karoke 
NAV Pekanbaru terhadap indikator assurance/ jaminan adalah baik atau positif.

Untuk memahami keinginan konsumen diperlukan kesabaran yang tinggi oleh setiap karyawan karaoke, berusaha memberikan simpati yang tinggi kepada para pelanggannya, agar tercipta kenyamanan bagi konsumen yang datang ke tempat karaoke. Berikut tanggapan konsumen terhadap indikator emphaty/ empati di NAV karaoke Pekanbaru, untuk variabel emphaty mempunyai bobot kisaran teoritisnya antara 7 sampai dengan 35 dengan rata-rata sebesar 21. Pada kisaran sesungguhnya variabel emphaty mempunyai bobot jawaban antara 27 sampai dengan 35 dengan rata-rata sebesar 31,40. Dapat dilihat bahwa nilai ratarata jawaban atas variabel emphaty bobot jawaban kisaran sesungguhnya berada di atas rata-rata kisaran teoritis, maka dapat disimpulkan bahwa pengaruh variabel emphaty terhadap responden adalah tinggi, dan persepsi konsumen pada NAV karaoke Pekanbaru terhadap indikator assurancel jaminan adalah baik atau positif.

Statistik deskriptif mengenai variabelvariabel penelitian meliputi persepsi pengunjung terhadap kualitas layanan yang terdiri dari tangible, reliability, responsiveness, assurance dan emphaty secara total disajikan dalam tabel yang menunjukkan angka kisaran teoritis, kisaran sesungguhnya, rata-rata dan standar deviasi. Pada tabel tersebut disajikan kisaran teoritis yang merupakan kisaran atas bobot jawaban yang secara teoritis didesain dalam kuesioner dan kisaran sesungguhnya yaitu nilai terendah sampai nilai tertinggi atas bobot jawaban responden yang sesungguhnya.

\begin{tabular}{l|c|c|c|c|c|}
\multicolumn{7}{c}{ STATISTIK DESKRIPTIF } \\
\hline \multirow{2}{*}{ Variabel } & \multicolumn{2}{|c|}{ Teoritis } & \multicolumn{2}{c|}{ Sesungguhnya } & Standar \\
& Kisaran & Mean & Kisaran & mean & Deviasi \\
\hline Tangible & $10-50$ & 30 & $35-50$ & 43,15 & 4,860 \\
Reliability & $9-45$ & 27 & $33-45$ & 38,18 & 3,587 \\
Responsiveness & $8-40$ & 24 & $28-40$ & 33,55 & 3,537 \\
Assurance & $10-50$ & 30 & $32-50$ & 41,22 & 5,686 \\
Emphaty & $7-35$ & 21 & $27-35$ & 31,40 & 2,916 \\
$\begin{array}{l}\text { Persepsi pengunjung } \\
\text { terhadap kualitas } \\
\text { pelayanan (total) }\end{array}$ & $44-220$ & 132 & $155-220$ & 187,50 & 20,586 \\
\hline
\end{tabular}

Jika dilihat dari persepsi pengunjung terhadap kualitas pelayanan secara total dalam tabel di atas, kisaran skor jawaban teoritisnya terendah 44 dan tertinggi 220 dan kisaran jawaban sesungguhnya terendah 155 dan tertinggi 220. Angka tersebut menunjukkan kecenderungan bahwa secara umum pengunjung memiliki pemahaman yang baik atas kualitas pelayanan. Hal ini dibuktikan dengan tingginya persepsi pengunjung secara umum terhadap kualitas pelayanan, dengan skor total jawaban terendah sebesar 155 diatas rata-rata kisaran teoritis total yaitu sebesar 132 .

\section{SIMPULAN}

Berdasarkan hasil penulisan dan pengamatan penulis, dapat di ambil kesimpulan sebagai berikut : Berdasarkan hasil wawancara peneliti dengan supervisor NAV karaoke Pekanbaru dapat diambil kesimpulan, bahwa manajemen NAV karaoke Pekanbaru telah mempersiapkan upaya-upaya untuk meningkatkan kualitas pelayanan dan peraturan-peraturan bagi pelanggan dan karyawannya.

Pada data demografi pengunjung yang memberikan persepsinya terhadap kualitas pelayanan NAV karaoke Pekanbaru, diketahui bahwa mayoritas berjenis kelamin laki-laki, berusia 17-27 tahun, pendidikan terakhir SMA, bertempat tinggal di Pekanbaru dan pekerjaan sebagai mahasiswa. Rata-rata pengunjung berkunjung selama 1-4 jam, memilih jenis ruangan medium, menggemari lagu pop dan berkunjung pada malam hari.

Berdasarkan hasil analisa yang telah penulis dapatkan maka dapat disimpulkan bahwa persepsi pengunjung terhadap kualitas pelayanan NAV karaoke Pekanbaru secara keseluruhan adalah baik/positif. Diantara lima variabel yang di analisa, variabel yang di nilai paling baik oleh pengunjung NAV karaoke Pekanbaru adalah variabel tangible/ bukti fisik. 


\section{DAFTAR RUJUKAN}

Amelia, R. 2013. Analisa Pengaruh Kualitas Pelayanan Terhadap Kepuasan Konsumen. Binus University. Jakarta.

Arikunto, S. 2010. Prosedur Penelitian, Suatu Pendekatan Praktik. Jakarta: Rineka Cipta.

Balai Peningkatan dan Pariwisata, 1992, Meningkatkan Efektivitas Fungsi Supervisor dan Pelayanan Pelanggan, Bandung.

Basuki, S. 2006. Metode Penelitian. Jakarta: Wedatama Widya Sastra dan Fakultas Ilmu Pengetahuan Budaya Universitas Indonesia

Benardine, R. Wirjana, M.S.W dan Supardo, S. 2006, Kepemimpinan Dasardasar dan pengembangannya, C.V Andi Offset, Yogyakarta.

Black, J. M. 1993. Management and Supervisor. Balai Pustaka. Jakarta.

Gasperz, V. 1997. Manajemen Kualitas: Penerapan Konsep-Konsep Kualitas dalam Manajemen Bisnis Total. PT Gramedia Pustaka Utama. Jakarta.

Gibson, J. L., et al. 1996. Organisasi, Perilaku, Struktur,danProses. Alih Bahasa oleh Nunuk Andiarni, jilid 1 dan 2. Jakarta : Binarupa Aksara.

Kotler, P., and Amstrong, G. 2007. Dasardasar Pemasaran Edisi Kesembilan Jilid 1, PT Indeks, Jakarta

Ludigdo, U. dan Machfoedz. 1999. Persepsi Akuntan dan Mahasiswa terhadap Etika Bisnis. Jurnal Riset Akuntansi Indonesia. Vol.2 Jan: 1-9.
Lupiyado, R. 2001. Manajemen Pemasaran Jasa (Teori dan Praktik). Jakarta. PT Salemba Emban Patria

Margono. 2004. Metodologi Penelitian Pendidikan. Jakarta: Rineka Cipta

Marsum, W. A. 2005. Restoran dan Segala Permasalahannya. Andi. Yogyakarta.

Merryani, E. O., Rompas, S., dan Pondang, L. 2014. Faktor-Faktor yang Berhubungan dengan Tingkat Kepuasan Pasien Rawat Inap Terhadap Pelayanan keperawatan Diruang Internal RSUD Noongan. Universitas Sam Ratulangi. Manado.

Nurlistiya, W. 2009. Analisis Pengaruh Variabel Kualitas Pelayanan Terhadap kepuasan konsumen pada Nav Karaoke Cabang Depok. Universitas Gunadarma. Jakarta Timur.

Rahmad, A. 2012. Analisis Persepsi Konsumen Terhadap Pelayanan Karaoke Inul Vizta family Outlet cabang Kota Jambi. ISSN. Jambi.

Rakhmat, J. 2003. Psikologi Komunikasi. Bandung : Remaja Rosdakarya.

Rangkuti, F. 2006. Teknik Mengukur dan Strategi Meningkatkan Kepuasan Pelanggan. Pt Gramedia Pustaka Utama. Jakarta.

Retnowati. 2005. Persepsi Remaja Ketergantungan Napza Mengenai Dukungan Keluarga Selama Masa Rehablitasi. htttp://www.kesehatan.go.id. diakses 05/05/2009

Robbins, P. S., dan Judge. 2008. Perilaku Organisasi. Edisi Dua belas. Penerbit Salemba Empat: Jakarta 
Robbins, P. S. 2002. Prinsip-prinsip Perlaku Organisasi. Edisi kelima. Penerbit Erlangga. Jakarta

Sekaran, U. 2006. Research Methods For Business. Salemba Empat. Jakarta.

Soekresno dan I.N.R. Pendit, 1996, Petunjuk Praktek Pramusaji Food and Beverage Service Buku Panduan Sekolah Pariwisata dan Perhotelan, PT Gramedia Pustaka Utama, Jakarta.

Sugiyono. 2012. Metode Penelitian Administrasi dengan Metode $R \& D$. Bandung: CV Alfabeta.

Thoha, M. 2008. Perilaku Organisasi : Konsep Dasar dan Aplikasinya. Jakarta: Raja Grafindo Persada , 2003, Perilaku Organisasi, Edisi Pertama, Cetakan Keempatbelas, PT Raja Grafindo Persada, Jakarta.

Tjiptono, F. 2005. Pemasaran Jasa. Edisi Pertama. Cetakan Pertama. Malang: Bayumedia Publishing

Tjiptono, F., \& Chandra, G. 2011. Service, Quality \& Satisfaction. Yogyakarta: ANDI.

Yoeti, A.O. 2004. Strategi Pemasaran Hotel. Jakarta: PT.Gramedia Pustaka Utama. 